\title{
Does permanent income determine the vote?*
}

\author{
Jo Thori Lind ${ }^{\dagger}$
}

August 17, 2004

\begin{abstract}
I study to what extent voters are forward looking and how future income affects the voting decision. Particularly, I estimate the effect of both transitory and permanent income on preferences for different parties using a panel data set from the Norwegian Election Study. To construct a proxy for permanent income, I use stated expectations about the future economic situation and an estimate of how this affects future income. It turns out that once we include the proxy for permanent income, transitory income has no explanatory power on voting behaviour, supporting the hypothesis of forward looking voting. As expected, a high expected permanent income leads to Conservative voting and a low income to Socialist voting.
\end{abstract}

JEL Codes: C25, D31, D72, D91, H11, H53

Keywords: Voting, permanent income, redistribution

${ }^{*}$ I whish to thank Daron Acemoglu, Bill Kerr, Kalle Moene, and Per Krusell as well as seminar participants at MIT for helpful comments and discussions.

${ }^{\dagger}$ Department of Economics, University of Oslo, PB 1095 Blindern, 0317 Oslo, Norway. E-mail: j.t.lind@econ.uio.no 


\section{Introduction}

It is usually believed that on average, poor persons are more in favour of redistribution than rich persons as they pay a smaller share of the burden of the welfare state and often receive a larger benefit. This conjecture also finds empirical support: Preferences for tax cuts and cuts in redistributive programs is more widespread among the rich than the poor. The relationship between a person's permanent income and her opinions about redistribution and party choice has been less studied. As we believe people at least to some extent look ahead when making choices, this relationship is important for understanding how the distribution of income influences support for redistribution and the welfare state.

In this paper, I first examine to what extent voters are forward looking. Modern economic theory, building on the work of e.g. Friedman (1957), usually postulate that agents are rational and forward looking. If this is true, then not only income today, but also the path one expects it to take in the future, summarized by the permanent income, could matter for voting behaviour. I show that this is the case if there are costs of changing policies from one period to the next, so there is a status quo bias. When watching the political debate, however, it often seems that voter has shorter horizon, so it is not clear that permanent income is the only thing that matters. I study empirically which of the two components matter the most.

Second, the effect of income on party preferences are not necessarily the same when we study permanent income than transitory income, which is what has been used in most studies. Hence we also gain additional insight into the relationship between high income and conservative voting by understanding to what extent voters are forward looking.

To study these two questions, I use data from the Norwegian Election Surveys from 1977 to 1997. To construct a proxy for permanent income, I use the answer to questions regarding respondent's expectations about their economic future to identify the difference between the effects of permanent and transitory income. The data set is a rotating panel with two observations on every individual. This means that I can estimate how income and expectations today affect income and expectations next period. From these estimates, I construct a measure of expected discounted future income. As long as expectations do not have a direct effect on voting behaviour, this procedure permits separation of the effects of permanent and transitory income. 
It turns out that voting behaviour is almost entirely determined by permanent income, leaving no role for transitory income. Consequently, using transitory income in empirical studies is likely to give biased results. Furthermore, permanent income has the expected effect of making Conservative voting more likely and Socialist voting less likely. Both of these effects are strongly significant. Hence it seems that voters are forward looking when casting their votes, and the voting behaviour seems to correspond reasonably well to the one derived from standard political economy models.

The paper complements several strands of literature. First, there is a literature studying the relationship between income and preferences for redistribution. The general finding in this literature, which is surprisingly scarce, is a negative, although often quite weak, relationship between income and preferences in favour of redistribution. I survey some of this literature in Lind (2004). In that paper, I study the relationship between transitory income and voting, using a fixed effects panel data estimator to control for unobserved individual characteristics. The principal finding is that high income tends to lower the support for redistribution and induce Conservative voting, but the effect is strongly reduced by correcting for individual specific unobserved effects. Both my own work and the earlier contributions in this tradition only look at transitory income, which may understate the effect of income on party choice if permanent income is what really matters.

There is also an empirical literature studying how prospects of upward economic mobility reduces support for redistribution (Alesina and La Ferrara 2002, Corneo and Grüner 2002, Ravallion and Lokshin 2000), as well as some studies relating expected future economic situation to preferences (e.g. Husted 1989). These findings are related to Bénabou and Ok's (2001) theoretical model where they explain how social mobility may explain the lack of support of redistribution when the median voter is poorer than the mean. This literature, however, is less suitable to study the general relationship between income and redistribution, and then also how the income distribution affects policy. Indirectly, the paper also relates to the empirical literature of permanent income and consumption surveyed by e.g. Deaton (1992) and Browning and Lusardi (1996), but the object of scrutiny is different.

There are also several papers that construct dynamic political economy models. Krusell, 
Quadrini, and Ríos-Rull (1997) and Krusell and Ríos-Rull (1999) extend the basic model of Meltzer and Richard (1981) to a dynamic and stochastic economy where agents are rational and forward looking. As politics today will affect investments, and hence the economy tomorrow, the dynamic politico-economic equilibrium becomes more complicated than the standard static case. This reasoning is taken further by Hassler et al. (2003a,b) who construct overlapping generations models to study both the dynamic effects of policies and the conflict between generations. This literature is overwhelmingly theoretical. One objective of this paper is to make an attempt of taking this literature to the data.

\section{Theoretical model}

Before embarking in the empirical model, I will present a simple dynamic model of policy formation. Although this is not the exact model estimated later on, it is useful both to clarify the processes I study and to see one channel through which future income may have an impact on political preferences today.

Consider an economy consisting of a continuum of infinitely lived agents with unit measure. Time is discrete. To simplify, I abstract from endogenous labour supply so in every period $t$ agent $i$ gets an exogenous income $y_{i t}$. She also gets a signal $s_{t}$ about her future income. This may be any information about future changes in income, such as the prospect of a promotion or knowledge of a high probability of unemployment. For notational simplicity I treat $s_{t}$ as a scalar, but this is trivial to extend. Jointly $\left(y_{t}, s_{t}\right)$ follows a Markov process. Denote by $F\left(y_{t} ; y_{t-1}, s_{t-1}\right)$ the probability of an income below $y_{i t}$ if the agent had income $y_{t-1}$ and received a signal $s_{t-1}$ last period, so $F$ is the cumulative distribution function of $y_{t}$. A high income today increases the probability of a high income tomorrow. Particularly, I will assume that $F\left(y_{t} ; y_{t-1}, s_{t-1}\right) \geq F\left(y_{t} ; y_{t-1}+\delta, s_{t-1}\right)$ for $\delta>0$ and any $y_{t}$ so we have stochastic dominance. Similarly, $s_{t}$ is a positive signal so $F\left(y_{t} ; y_{t-1}, s_{t-1}\right) \geq F\left(y_{t} ; y_{t-1}, s_{t-1}+\delta\right)$ for $\delta>0$ and any $y_{t}$.

Denote the joint distribution of income and signals at time $t$ by $\mathcal{F}_{t}$. I assume that $\left\{y_{t}, s_{t}\right\}_{t=0}^{\infty}$ follows an ergodic process, ${ }^{1}$ so the income distributions $\mathcal{F}_{t}$ will converge to a

\footnotetext{
${ }^{1}$ I take ergodicity simply to mean that the Markov process converges to an invariant distribution. For a formal definition, see e.g. White (1984, Definition 3.33). Otherwise, see Stokey and Lucas (1989, Ch.
} 
stable distribution $\mathcal{F}$. I only study the steady state, so this means that the distribution is constant. Denote by $\bar{y}$ the average income. When we abstract from economic growth, a constant distribution of income does not seem like an unrealistic assumption. If we have growth, then there could also be an income effect. However, in the present model, this would not be the case.

Wage income is subject to a linear tax $\tau_{t}$ which is used for a lump sum redistribution so each agent receives a transfer $T\left(\tau_{t}\right) \bar{y}$ where $T$ may capture possible dead weight losses. It is easy to construct micro foundations for this function from a model of endogenous labour supply, but I do not introduce this into the model to keep it as simple as possible. I make the standard assumptions that the dead weight loss is absent at $\tau=0$ and increases as $\tau$ increases. This implies that $T$ satisfies $T(0)=0, T^{\prime}(0)=1, T^{\prime}(\tau) \leq 1$, and $T^{\prime \prime}(\tau)<0$, that is, a concave Laffer curve. For simplicity, I will also assume that $T^{\prime}(1)<0$ so $T$ is maximized for a tax rate strictly below one.

Then an agent with pre-tax income $y_{t}$ has a post tax income $\left(1-\tau_{t}\right) y_{t}+T\left(\tau_{t}\right) \bar{y}$. This means that the tax base is exogenous. I could also introduce taxation of capital income. Taxes would then have a deeper dynamic effect as the chosen tax would depend on the distribution of both assets and wage income. It would not be possible to solve this model analytically, so I remain from this for tractability. An endogenous tax base would introduce an additional cost of taxes as saving would get more costly. Nevertheless, the concavity of $T$ already picks up this element, so it would not introduce anything substantially new to the model.

Income may either be used for consumption $c_{t}$ or saving for the next period. Total assets left from period $t$ to period $t+1$ is denoted by $\alpha_{t+1}$. Assets yield a rate of interest rate $r$, which is constant, possibly due to access to an international capital market. ${ }^{2}$ Each agent has a concave instantaneous utility function $u$ and a discount rate $\theta$. She then maximizes

$$
V\left(a_{0}, \mathcal{F}_{0}\right)=E\left[\sum_{t=0}^{\infty} \theta^{t} u\left(c_{t}\right) \mid \Omega_{0}\right]
$$

11) for general conditions for convergence of Markov chains.

${ }^{2}$ In a closed economy, policies could affect $r$ so we get dynamic effects. However, this seems to me to be a very indirect effect of policies, so this is not a strong assumption. 
with regard to the consumption path subject to

$$
a_{t+1}=\left(1-\tau_{t}\right) y_{t}+T\left(\tau_{t}\right) \bar{y}+(1+r) a_{t}-c_{t}, \forall t
$$

and the transversality condition. $\Omega_{t}$ is the information set at date $t$, which, given the assumptions of the model, contains the histories $\left\{y_{k}, s_{k}\right\}_{k=0}^{t}$. The income distribution $\mathcal{F}_{0}$ enters the value function as taxes are determined politically, and hence depend on it. Due to the Markov structure of the economy, the important elements of $\Omega_{t}$ are $\left(y_{t}, s_{t}\right)$. This gives rise to the Bellman equation

$$
V(a, \mathcal{F})=\max _{a^{\prime}} u\left[\left(1-\tau_{t}\right) y+T\left(\tau_{t}\right) \bar{y}+(1+r) a-a^{\prime}\right]+\theta E\left[V\left(a^{\prime}, \mathcal{F}^{\prime}\right) \mid \Omega\right]
$$

where variables without primes denote current values and variables with primes variables next period. This yields the usual first order condition $u^{\prime}\left(c_{t}\right)=\theta E\left[V^{\prime}\left(a_{t+1}\right) \mid y, s\right]$, which together with the envelope theorem yields the Euler equation

$$
u^{\prime}\left(c_{t}\right)=\theta(1+r) E\left[u^{\prime}\left(c_{t+1}\right) \mid \Omega\right]
$$

So far, I have taken the tax rates in each period as given. However, the objective of the model is to study how taxes are determined. Consider first a case with no policy persistence. Taxes are voter over each period, and when there is no persistence, all that matters is this period's distribution of income as the tax base is exogeneous. Than each agent will prefer the tax that maximizes her post tax income, so in period $t$, an agent with income $y_{t}$ has a preferred tax rate

$$
\tau^{*}\left(y_{t}\right)= \begin{cases}T^{-1}\left(y_{t} / \bar{y}\right) & \text { if } y_{t}<T^{\prime}(0) \bar{y} \\ 0 & \text { otherwise }\end{cases}
$$

where $T^{\prime-1}$ is the inverse of $T^{\prime}$. As $T$ is concave, it is clear that $\tau^{*}$ is non-increasing in $y_{t}$. If the tax rate is chosen independently each period, the chosen tax rate is $\tau^{*}\left(y^{m}\right)$ where $y^{m}$ is the median income. In this case, only the current income will matter for tax preferences.

However, large policy changes usually takes time to implement, so it may be that the tax rate is not independently chosen each year. We could model this by saying that if we choose a policy today, the implemented policy is a weighted average of this period's and last period's policy. Alternatively, a change in policy today will only take full effect after 
a given number of periods. However, both have in common that by choosing sufficiently extreme policies today, any chosen policy is implementable at every period as long as the agents are fully rational and knows the policy formation process. A more satisfactory, and also plausible assumption is that there are cost of changing policies. Coate and Morris (1999) present a model explaining why this may be the case. To capture this, if last periods tax rate was $\tau$ and society decides to implement a tax $\tau^{\prime}$ this period, I assume that all agents incur a cost $c\left(\tau^{\prime}-\tau\right)$ where $c$ is a convex function with a minimum at 0 . Then (2) becomes

$V(a, \tau, \mathcal{F})=\max _{a^{\prime}} u\left[\left(1-\tau^{\prime}\right) y+T\left(\tau^{\prime}\right) \bar{y}+(1+r) a-a^{\prime}\right]+c\left(\tau^{\prime}-\tau\right)+\theta E\left[V\left(a^{\prime}, \tau^{\prime}, \mathcal{F}^{\prime}\right) \mid \Omega\right]$

As $\tau^{\prime}$ is determined politically, the maximization in (4) is only over $a^{\prime}$ and not $\tau^{\prime}$ which is determined by a political mechanism, say as the preferred tax rate of the median voter. Each particular agent's preferred tax rate is found by maximizing $V$ with regard to $\tau^{\prime}$. This yields a function $\tau^{*}\left(y_{t}, s_{t}\right)$, which in general is different from (3) as there may dynamic effects. This is also the reason why $s_{t}$ enters the function. It is easily seen that $\tau^{*}$ is continuous and non-increasing in both arguments. Assuming that $\mathcal{F}$ is a continuous distribution, this implies that there are connected loci of points in $\left(y_{t}, s_{t}\right)$-space where agents have identical preferred taxes. One such has the property that the measure of agents that prefer a tax rate both below and above this rate is less then or equal to $1 / 2$. This is then the median preferred tax, and the one that would be chosen by a median voter procedure, such as a Downsian party system. Call this tax rate $\tau^{m}$. It will remain unchanged over time when $\mathcal{F}$ is constant, which it is in the steady state.

The voters take this into account when they make up their political preferences in the sense that a change in policy will have an effect both in this period and in the future. The first is trivial. The reason for the second is that the median voter incurs a cost from changing the tax rate back to $\tau^{m}$, and as the cost function is convex, she will not return to her preferred tax policy in one big leap. An initial policy change $\tau$ at time $t$ will then lead to a sequence of new policies $\left\{\tau_{i}^{\tau}\right\}_{i=1}^{\infty}$ that satisfies

$$
U^{\prime}\left(\tau_{i}^{\tau}\right)+c^{\prime}\left(\tau_{i}^{\tau}-\tau_{i-1}^{\tau}\right)-\theta c^{\prime}\left(\tau_{i+1}^{\tau}-\tau_{i}^{\tau}\right)
$$

where $\tau_{0}^{\tau}=\tau$ and $U(\tau)$ is the median voter's instantaneous utility of consumption given 
a tax rate $\tau$. Implicit differentiation yields

$$
\frac{d \tau_{i}^{\tau}}{d \tau_{i-1}^{\tau}}=\frac{c^{\prime \prime}\left(\tau_{i}^{\tau}-\tau_{i-1}^{\tau}\right)}{U^{\prime \prime}\left(\tau_{i}^{\tau}\right)+c^{\prime \prime}\left(\tau_{i}^{\tau}-\tau_{i-1}^{\tau}\right)-\theta c^{\prime \prime}\left(\tau_{i+1}^{\tau}-\tau_{i}^{\tau}\right)\left(\frac{d \tau_{i+1}^{\tau}}{d \tau_{i}^{\tau}}-1\right)} \in[0,1)
$$

as $c$ is convex and $U^{\prime \prime}(\tau)<0$ so the absolute value of the denominator is lager than that of the numerator with both being negative. Hence $\left\{\tau_{i}^{\tau}\right\}_{i=1}^{\infty}$ is convergent, so $\tau_{i}^{\tau} \rightarrow \tau^{m}$ as $i \rightarrow \infty$. To conclude, a one period change in policy will change the median voter's chosen policy in the same direction for the periods that follow, but her preferred tax rate will converge back to $\tau^{*}$.

We now see that

$$
\frac{\partial V(a, \tau, \mathcal{F})}{\partial \tau}=E\left[\sum_{s=t}^{\infty} \theta^{s} U^{\prime}\left(\tau_{s}^{\tau}\right) \frac{\partial \tau_{s}^{t}}{\partial \tau} \mid \Omega_{0}\right]
$$

where $\partial \tau_{s}^{\tau} / \partial \tau$ can be found by iterated use of (5). The Euler equation says that the expected marginal utility of consumption should be equal in each period. Hence we get

$$
\frac{\partial V(a, \tau, \mathcal{F})}{\partial \tau}=u^{\prime}(c) E\left[\sum_{k=0}^{\infty}\left(\frac{1}{1+r}\right)^{k}\left[T^{\prime}\left(\tau^{(k)}\right) \bar{y}-\left(1+\Upsilon^{(k)}\right) y^{(k)}\right] \frac{\partial \tau_{s}^{t}}{\partial \tau} \mid \Omega\right]
$$

where a superscript $(k)$ means a variable $k$ periods ahead and

$$
\Upsilon^{(s)}=\operatorname{cov}\left(\frac{u^{\prime}\left(c^{(k)}\right)}{E\left[u^{\prime}\left(c^{(k)}\right) \mid \Omega\right]}, \frac{y^{(k)}}{E\left[y^{(k)} \mid \Omega\right]} \mid \Omega\right)
$$

the covariance of the normalized $u^{\prime}\left(c^{(k)}\right)$ and $y^{(k)}$. When consumers smooth consumption, $\Upsilon^{(s)}$ is close to zero. If we for simplicity ignore $\Upsilon^{(k)}$, the result is parallel to the independence between the consumption and investment decisions. This tells us that an increase in income has two effects on tax preferences. The direct effect is that higher income today leads to a lower desired tax today. As $y \in \Omega$, there is also an indirect effect as higher income today increases the expected income tomorrow. As policy is persistent, this strengthens the voter's preferences for a low tax to try to get more out of here expected high income next period. Second, as also $s \in \Omega$, (6) tells us that an increase in $s$, the belief in an improved situation in the future, will increase the expectation of income next period, and hence reduce the preferred tax rate if $\partial \tau_{s}^{t} / \partial \tau>0$. This effect is similar to the indirect effect of a rise in income.

When policy changes are costly, so policies are persistent, the model tells us that rational forward looking voters should put no particular emphasis on today's income, but 
let their permanent income determine who they vote for. However, income should be discounted at a higher rate than usual to reflect the limited persistence of politics. In the remaining parts of the paper, we are going to test this conclusion.

\section{Empirical specification of voting behaviour}

The theoretical model set out above predicts that preferences for high taxes are falling in today's income and expected income in the future. To test the hypothesis of forward looking voters, I will estimate the effect of transitory and permanent income on voting behaviour to see which has the largest explanatory power.

Although the argument above was set out in a simple model of direct democracy, it would also hold for a two-party system with tax policy as the sole issue (Downs 1957). In a system of multiple parties and/or political issues, the analysis would become more complicated. Although crosscutting cleavages could alter the main conclusions (Roemer 1998, 1999), I believe it is reasonable to still assume that support for conservative parties would be increasing in today's income and expectations about future income.

For simplicity, I will only consider today's income and the permanent income to matter in the baseline empirical specification. We can then study to what extent permanent income affects voting relative to transitory income. The study is done within a random utility framework. We may think of this as an extension of the model above to a probabilistic voting model. Assume that agent $i$ gets utility

$$
v_{i t j}=\alpha_{i j t}+\beta_{j}\left[\zeta y_{i t}+(1-\zeta) y_{i t}^{*}\right]+\gamma_{j} z_{i t}+\varepsilon_{i j t}
$$

from voting party $j$ at time $t$. $a_{i j t}$ is a constant term I will discuss further below and $z_{i t}$ is a vector of other individual characteristics. $\beta_{j}$ gives the effect of income on preferences for party $j$. The relevant measure of income is a weighted average of income in period $t, y_{i t}$, and the agent's estimate of her permanent income $y_{i t}^{*}$, where she puts weight $\zeta \in[0,1]$ on the former and $1-\zeta$ on the latter. The residual $\varepsilon_{i j t}$ is assumed to have a standard extreme value distribution, so the choice probabilities have a logistic structure. Notice that the utility function (7) is a mere tool for ranking parties, and should not be confounded with the utility function (1). 
As I argue in Lind (2004), it is likely that unobserved factors such as social background and experiences affect voting behaviour. These factors are also likely to be correlated with income, so an ordinary logit estimation where these factors are omitted is likely to overestimate the effect of income on voting. To correct for this, I suggest to use panel data. I consider two specifications. First, a simple random effects specification where $\alpha_{i j t}$ consists of a time dummy and an individual effect that is normally distributed and independent of other variables, an second a fixed effects estimator where $\alpha_{i j t}$ consists of a period dummy and an individual specific dummy. I also made some attempts using an intermediate specification due to Chamberlain (1980) where $a_{i j t}$ is random, but depends linearly on the across periods mean of income. This gave very similar results so for reasons of space I omit them.

Estimation of the random effects estimator is fairly standard. I use simulated maximum likelihood were a set of draws of $a_{i j t}$ with a given variance-covariance matrix is drawn, and the likelihood function is approximated using Monte Carlo integration. Antithetic variates are used to improve the accuracy of the approximation. To estimate the fixed effects model, I follow Chamberlain $(1980,1984)$ in conditioning on the choices made at some time, and using the order of choice to estimate the parameters, again using maximum likelihood. See Lind (2004) for further details on the implementation of both estimators.

\section{Empirical specification of expectations}

For obvious reasons I don't have data on the respondents' expectations, so I have to attempt to proxy for these. Above I assumed that agents receive a signal $s_{i t}$ about their future income. Let us now extend this to a $n$-vector and assume they do not directly affect political preferences today. ${ }^{3}$ This assumption is the one that will let us identify the effect of permanent versus transitory income. The signal I use is a set of dummies on subjective opinions on the future economic situation of the agent. I will assume that income and the vector of signals follow a simple first order vector autoregressive process,

\footnotetext{
${ }^{3}$ As long as we have at least one signal without a direct impact on voting, we may very well have other signals that also have a direct impact. For simplicity, I abstract from this.
} 
so we can write

$$
\left(\begin{array}{c}
y_{i, t+1} \\
s_{i, t+1}
\end{array}\right)=\kappa+\Pi\left(\begin{array}{c}
y_{i t} \\
s_{i t}
\end{array}\right)+u_{i t}
$$

where $\kappa$ is a vector of constants, $\Pi$ a matrix of parameters and $u_{i t}$ a vector of mean zero random shocks. From a panel data set, we can estimate the effect of the signal on future income, and then infer the effect of a given signal on the permanent income.

It is tempting to let one time period denote one electoral period, i.e. four years. However, there are two reasons why this is not appropriate. First, in the data set I use, respondents are asked to state their income last year, as this year's income is not yet known at the time of the interview. Second, the signals $s_{i t}$ may very well have an impact on income before the next elections. Hence I will take one period to signify one year. Then we have data on $y_{i, t-1}, y_{i, t+3}, s_{i t}$, and $s_{i, t+4}$. As we only observe $\left\{y_{i t}, s_{i t}\right\}_{t=0}^{\infty}$ every four periods, we need additional assumptions to identify $\Pi .{ }^{4}$ Particularly, I assume that each element of $s_{i, t+1}$ only depends on that element of $s_{i t}$, not on the other signals or income at time $t$. Then $\Pi$ has the structure

$$
\Pi=\left(\begin{array}{cccc}
\phi & \delta_{1} & \cdots & \delta_{n} \\
0 & \pi_{1} & \cdots & 0 \\
0 & \vdots & \ddots & \vdots \\
0 & 0 & \cdots & \pi_{n}
\end{array}\right) .
$$

This is a strong assumption, but it seems rather plausible. Also, I cannot reject this structure on the data I use. From this structure on $\Pi$, it follows that for $k \geq 1$

$$
y_{i, t+k}=A+\phi^{k+1} y_{t-1}+\sum_{q=1}^{n}\left(\sum_{j=0}^{k-1} \phi^{k-1-j} \pi^{j}\right) \delta_{q} s_{q i t}
$$

where $A$ is a constant and $s_{q i t}$ is the $q$ 'th element of $s_{i t}$. To estimate the parameters, we first regress each $s_{q i, t+4}$ on $s_{q i t}$ to obtain estimates of $\pi_{q}^{4}$ which we can solve for $\pi_{q} \cdot{ }^{5}$ Second, we regress $y_{i, t+3}$ on $y_{i, t-1}$ and $s_{i t}$. The parameter on $y_{i, t-1}$ is an estimate of $\phi^{4}$ which may be solved for $\phi$. The parameters on the signals are estimates of $\left(\phi^{2}+\phi \pi_{q}+\pi_{q}^{2}\right) \delta_{q}$, which is easily solved for $\delta_{q}$ once we know $\phi$ and $\pi_{q}$.

\footnotetext{
${ }^{4}$ Essentially, the problem is that we cannot derive $\Pi$ from knowledge of $\Pi^{4}$.

${ }^{5}$ The sign is not identified, but it is natural to assume it positive.
} 
The agent's expected permanent income at time $t$, given her information set $\Omega_{t}$, is

$$
\begin{aligned}
E\left[y_{i t}^{*} \mid \Omega_{t}\right] & =(1-\lambda) \sum_{s=t}^{\infty} \lambda^{s-t} E\left(y_{i s} \mid \Omega_{t}\right) \\
& =\pi_{c}+(1-\lambda) \sum_{s=t}^{\infty} \iota \lambda^{s-t} \Pi^{s-t}\left(\begin{array}{c}
y_{i t} \\
s_{i t}
\end{array}\right)+\iota E\left(u_{i t}^{*} \mid \Omega_{t}\right) \\
& =\pi_{c}+\iota(1-\lambda)(I-\lambda \Pi)^{-1}\left(\begin{array}{c}
y_{i t} \\
s_{i t}
\end{array}\right)+\iota E\left(u_{i t}^{*} \mid \Omega_{t}\right) \\
& =\pi_{c}+(1-\lambda)\left(\frac{\phi}{1-\lambda \phi} y_{i, t-1}+\sum_{q=1}^{n} \frac{\lambda \delta_{q}}{(1-\lambda \phi)\left(1-\lambda \pi_{q}\right)} s_{q i, t}\right)+\iota E\left(u_{i t}^{*} \mid \Omega_{t}\right)
\end{aligned}
$$

where $\lambda$ is the discount rate, $u_{i t}^{*}$ a linear combination of the $u_{i s}$ 's, $\iota$ the vector $\left(\begin{array}{cccc}1 & 0 & \cdots & 0\end{array}\right)$, $I$ the identity matrix, and $\pi_{c}$ a constant. The discount rate is not well identified from the present model, so I will simply assume a $5 \%$ annual rate which yields $\lambda=0.95$. Although the agent may have information about the permanent income unknown to the econometrician, so $E\left(u_{i t}^{*} \mid \Omega_{t}\right) \neq 0$, I will assume that it has expectation zero given the econometrician's information set (i.e. $\left.E\left(u_{i t}^{*} \mid\left(y_{i, t-1}, s_{t}\right)\right)=0\right)$. This will assure that the error term is uncorrelated with the regressors in the second stage of estimation.

Denote by $\pi_{y}:=(1-\lambda) \phi /(1-\lambda \phi)$ the effect of current income on permanent income and let $\pi_{s}$ denote the vector of $(1-\lambda) \lambda \delta_{q} /(1-\lambda \phi)\left(1-\lambda \pi_{q}\right)$, associated with the signals $s_{i t}$. Then $y_{i t}^{*}=\pi_{c}+\pi_{y} y_{i, t-1}+\pi_{s}^{\prime} s_{i t}$. Inserting into the utility function (7), we get

$$
\begin{aligned}
v_{i t j}= & \alpha_{i j t}+\beta_{j}(1-\zeta) \pi_{c}+\beta_{j}\left[\zeta+(1-\zeta) \pi_{y}\right] y_{i t}+\beta_{j}(1-\zeta) \pi_{s}^{\prime} s_{i t} \\
& +\gamma_{j} z_{i t}+\beta_{j}(1-\zeta) \iota E\left(u_{i t}^{*} \mid \Omega_{t}\right)+\varepsilon_{i j t} .
\end{aligned}
$$

Denote by $a$ and $b$ the parameters on $y_{i t}$ and $\pi_{s} s_{i t}$ from the logit model on party choice. Then we have

$$
\left\{\begin{array} { l } 
{ a = \beta _ { j } [ \zeta + ( 1 - \zeta ) \pi _ { y } ] } \\
{ b = \beta _ { j } ( 1 - \zeta ) }
\end{array} \Leftrightarrow \left\{\begin{array}{l}
\beta=a+\left(1-\pi_{y}\right) b \\
\zeta=\left[a-\pi_{y} b\right] /\left[a+\left(1-\pi_{y}\right) b\right],
\end{array}\right.\right.
$$

so the impact of income $\beta$ and the share of permanent income in the relevant measure of income $\zeta$ may be derived from the estimates of the VAR model (8) and the logit model (11).

Now estimation proceeds in a two step manner. First the VAR model (8) is estimated using first period income and observations on the signal and second period income. 
Second, the logit model (11) is estimated by maximum likelihood, using the estimated parameters from the first stage and the specifications of the individual specific term outlined above. Finally, $\beta$ and $\zeta$ are derived using (12). To show consistency of this two step estimator, denote by $S(\Pi)$ minus the total sum of squares for the VAR model (8) and $L(\Theta ; \Pi)$ the log likelihood of model $(11)$, where $\Theta$ are the parameters entering this model. We can now construct an M-estimator for $\Pi$ and $\Theta$ as the values that minimize $S(\Pi)+L(\Theta ; \Pi)$, and under the present conditions, consistency is assured (see e.g. van der Vaart (1998, ch. 5)). As $\Theta$ does not enter into $S$, we can maximize this function separately to obtain consistent estimates of $\Pi$. Call these $\hat{\Pi}$. As these are consistent, we can then plug them into $L$ to obtain consistent estimates of $\Theta$ by partial maximization of $L$ wrt. $\Theta$ given $\Pi$. Call these estimates $\hat{\Theta}$. As $\hat{\Pi}$ is an estimate, we cannot use standard results on the distribution of the maximum likelihood estimators to study the distribution of $\hat{\Theta}$. However, as $\hat{\Pi}$ is $\sqrt{n}$-consistent and $\hat{\Theta}$ may be treated as an estimate from an M-estimator with nuisance parameters, it follows from Theorem 5.31 in van der Vaart (1998) that the distribution of $\hat{\Theta}$ is standard normal, but usually with a different covariance matrix than the inverse Hessian of the log likelihood. Although we can construct analytical approximations, I prefer to rely on bootstrapping to estimate this matrix.

\section{Data}

The data are from the Norwegian Election Survey from 1977 to 1997, made available through the Norwegian Social Science Data Services. ${ }^{6}$ The survey is conducted during the months following every parliamentary election, which take place every 4 years. Hence we have six waves of data. Most respondents are interviewed after two consecutive elections creating a rotating panel data set. The exact questions vary from election to election, but for all elections we have data on party choice, the respondent's household's total income, basic demographic characteristics that are used as control variables, and the answer to a question on whether they believe their economic situation is going to improve, deteriorate, or stay unchanged in the future. I use the answer to this last question as the signal $s$ on future income. Hence in my specification, $s$ is a vector of dummy variables.

\footnotetext{
${ }^{6}$ See Kiberg et al. (2000) for a description of the data.
} 
For 1993 and 1997, we have the household's income in 1000 NOK. Before 1993, we only have data on which income interval the respondent's household is in. To make the data comparable across years, I assume the income distribution is log normal so I can use Monte Carlo integration to estimate the effect of income. ${ }^{7}$

Norway has a proportional electoral system, and a relatively large number of parties represented in parliament. I group the parties into five group: The Socialist parties consist of the Social Leftist party as well as the Norwegian Communist Party and the Workers' Communist Party. The Labour party is treated alone. As this is the largest party, I use it as the reference group. Then follows the Centre parties which consist of the Centre Party, the Liberal party (Venstre), the Liberal Popular Party, and the Christian Popular Party. The Conservative party (Høyre) and the Progress party are grouped alone. A small number of individuals casting their votes for different parties are trimmed from the sample. There is a quite general consensus by different researchers using different techniques that the order of presentation given her is a reasonable ordering from left to right of these parties (Rasch 2003).

\section{$6 \quad$ Estimation results}

As a reference point, Table 1 reports the estimates from two specifications of the baseline logit model (7). In both specifications, the weight on transitory income $\zeta$ is constrained to unity. For both specifications, I estimated the random effects model with the whole sample and the sub-sample that changes party, as well as the fixed effects specification, which only uses the latter sample. Income is measured relative to the period averages. In the first specification, reported in columns 1 to 3, regressors include income and the control variables, whereas the second specification, reported in columns 4 to 6 , also includes dummies for expectations of one's economic situation.

Table 1 about here

As we would expect, income has a positive effect on voting for the Conservative party. However, allowing for correlation between the individual effect and income by introducing

\footnotetext{
${ }^{7}$ The precise procedure as well as the estimates of the parameters of the log normal distributions for each year are given in Lind (2004).
} 
fixed effects, this effect is sharply reduced. This was studied in more detail in Lind (2004). We also notice that inclusion of the proxies in columns 4 to 6 have a small impact on the effect of income, although the estimated parameters are slightly smaller than those in the first part of the table. Second, the expectations about the economic situation seem to have a considerable impact on voting behaviour. The lower row of the table gives test statistics of likelihood ratio tests of the new proxies being insignificant. It is seen that this hypothesis is rejected, often at extreme significance. The signs of the parameters are also sensible: Prospects of a better economic situation induces right-wing voting whereas prospects of a worsened economic situation and fear of unemployment induces left-wing voting. This is also the case for the fixed effects estimator, so it seems that it is the expectations that influences voting, and not only left-wing voters being more pessimistic than right-wing voters. Finally, it is seen that the effect of expectations have a considerable effect on choice probabilities. Going from expecting no change in the economic situation to expecting an improvement has the same effect on preferences for voting Conservative as between one and two additional average incomes, i.e. between 1.25 and 2.5 standard deviations.

Let us now turn to the estimation procedure for the effects of permanent income outlined above. Table 2 reports results from the VAR model (8). The first three columns reports unrestricted estimates of $\Pi^{4}$. As expected, those who expect a better economic situation in the future on average have higher income growth than others, and vice versa for those who expect a worsened situation. However, the effect is not very large; $15 \%$ and $2.9 \%$ of the average income. The middle three columns report estimation of $\Pi^{4}$ where the restrictions from (9) are imposed. We notice that the parameter estimates are quantitatively very similar. The restrictions are rejected at the $5 \%$ level for the model of "Worse economy", essentially because "Better economy" has a significantly negative impact on this variable. However, this effect is quantitatively small, so I believe the restrictions (9) are quite innocent. Looking at the derived $\pi \mathrm{s}$, the effects on permanent income of expecting better and worse economic conditions are $6.5 \%$ and $3.5 \%$. Due to the non-linearity of the model, the standard errors of $\pi_{y}$ and $\pi_{s}$ are derived using bootstrapping. The same bootstraps indicate that the bias of the estimators are negligible.

Table 2 about here 
Table 3 reports results from the logit model (11). The parameters $a$ and $b$, reported on in the first half of the table, are the estimated parameters on $y_{i, t-1}$ and $\pi_{s}^{\prime} x_{i t}$, whereas $\beta$, the impact of the relevant measure of income on voting behaviour, and $\zeta$, the share of current income in this measure, both reported in the second half of the table, are derived using (12). The most striking feature is the estimates of $\zeta$ : They are almost all between -0.2 and -0.4 , and a number of them are significantly different from zero. This implies that current income has a negative impact on agents' relevant measure of income. Although it may seem plausible that permanent income is more important than current income, this result seems too strong.

\section{Table 3 about here}

An obvious problem with the above procedure is that the model (8) assumes that all agents are equal in the sense that, shocks absent, they will converge to the same income in the long run. This is unlikely to be the case, so estimation should include an individual specific term. Neglecting this will results in an upward bias of the autoregressive coefficient of income $\phi$, and then also an upward bias in $\pi_{y}$ as an income shock is seen has having a larger effect on permanent income than it really has. This will lead to erroneous estimates of $\zeta$.

The individual effects that should be in the VAR model are certainly correlated with income, so we should use fixed effects estimation. However, as the electoral data only has two observations per individual, I cannot do this using the present data. To get an idea of the bias, I have estimated a simple AR(1) model of income relative to period mean using data from the PSID from 1994 to $1997 .{ }^{8}$ Neglecting the fixed effect gives an estimate $\hat{\phi}=0.63$ (.0047) whereas the GMM fixed effects estimator of Arellano and Bond (1991) yields $\hat{\phi}=0.15(0.14) .{ }^{9}$ OLS on the electoral data gave $\hat{\phi}=0.87(0.0154)$. If we believe that the effect of ignoring the fixed effects are about the same on the Norwegian data as on the US data, this implies a $\phi$ of about 0.2 . Imposing this parameter on the VAR model

\footnotetext{
${ }^{8}$ It would of course be better to do this using comparable Norwegian data. However, at the time of writing, I have not been able to get access to panels of income data with sufficient length to run a fixed effects estimation of the AR model.

${ }^{9}$ The income variable used is FAMINC (total family income). No trimming or adjustment was undertaken. If we trim the sample by removing the upper and lower percentile, OLS gives .48 (.0039) whereas the fixed effects estimator gives .18 (.012), indicating an even stronger effects of including fixed effects.
} 
(8) yields the results reported in the last three columns of Table 2. Most importantly, we see that the estimate of $\pi_{y}$ is much smaller. This is because we had an estimate of $\phi$ that was too high, so it seemed as if income was more persistent than it really is, so the effect of an increase in income was taken to be higher than it really is. The new $\pi_{y}$ reflects that income in one period has a smaller impact on income in the future. Also $\pi_{s}$ is changed, but to a smaller extent.

Table 4 reports results from the logit analysis imposing $\phi=0.2$. These estimates seem more sensible. Most of the shares on transitory income $\zeta$ are numerically close to zero, and no parameters are significantly different from zero. As we would expect, the estimates of the income effects $\beta$ are very different from the ordinary logit estimates presented in Table 1. The income effect on the Conservative party is positive and numerically large in all specifications. Compared to Table 1, the estimated parameter values are huge. Although the parameter value is numerically smaller in the fixed effects specification than in the random effects models, the reduction is much smaller compared to the results reported in Table 1. The effect on the Socialist parties is also interesting. In Table 1 the income effect was insignificant, but slightly positive. Now it is negative and numerically quite large. Also, this effect is largest in the fixed effects model.

\section{Table 4 about here}

As $\zeta$, the share put on transitory income, was estimated close to zero, it is interesting to test whether $\zeta$ is significantly different from zero and study the effect on the estimated income parameters of imposing this restriction. Table 5 reports results from an estimation where we impose $\zeta=0$ and $\phi=.2$. We first notice that, using a likelihood ratio test, we cannot reject this restriction for the samples of party changers. For the random effects specifications using the whole sample, we can rejects the hypothesis. This seems to be mainly because $\zeta$ is significantly greater than zero for the Conservative party in the estimations in Table 4. Consequently, it seems that permanent income is the most relevant measure of income to determine party preferences. We also see that imposing $\zeta=0$ only has small effects on the estimated income effects. The impact on the Conservative party is large, positive, and significantly different from zero in all models. The effect on the Socialist parties is negative, rather large, but not significantly different from zero. ${ }^{10}$ The

\footnotetext{
${ }^{10}$ The current estimated standard errors are based on the negative inverse Hessian, which may be
} 
effects on the Centre and Progress parties are small and not significantly different from zero.

Table 5 about here

\section{$7 \quad$ Are voters really non-myopic?}

The results above indicate that transitory income has no effect on voting behaviour once permanent income is accounted for. There are two reasons why this may be surprising. First we usually believe people behave somewhat myopically, so they also should put more emphasis on today than the future. Second, unless political persistence is very high, even perfectly forward looking rational agents would put more emphasis on the next electoral period than the future ones as policies may be changed in the future.

One objection to the estimates above is that the discount factor was imposed at .95, which may be to high if policies are not too persistent. The value was chosen to get a strong contrast to the myopic voter who only looks at her transitory income. Ideally, the relevant discount factor should be estimated. However, as it is probably weakly identified, this is unlikely to give meaningful estimates. Also, attempts of estimation with lower discount factors indicate small changes in the estimates of $\zeta$, and the effect is rather a smaller estimate than a larger.

One possible explanation may be what we can label the "dream effect". At least for some voters, the statement that they expect their economic situation to improve in the future may simply mean that they hope it will improve in the future. They may anticipate this by voting Conservative today. However, as the economic future was based more on a hope than a certainty, the effect on income is on average weak. Together, these may tend to overstate the effect of permanent income on voting and hence explain both high $\beta$ s and low $\zeta$ s for the Conservative party. We could also have a similar "nightmare effect" for the Socialist party where fear of lower income and Socialist voting are correlated. If this is the case, the effect of an expected improvement should have a higher effect than today's income and expected worsening on Conservative voting whereas an expected worsening should have an exceptionally high effect on Socialist voting. Table 6 reports results

imprecise. Some preliminary attempts at estimating standard errors by the bootstrap indicates that the effect may be significant at least in the fixed effects case. 
from an estimation where I have disaggregated the effects of today's income, expected worsened economic situation, and expected better economic situation. We see that there is little evidence of any "dream effect" for the Conservative party as we don't get higher coefficients on "Better economy" than on the other predictors of future income. For the Socialist party, however, there seem to be some evidence of a "nightmare effect" as the impact of "Worse economy" is larger than the other predictors.

Table 6 about here

A related explanation is that agents may exhibit loss aversion, a concept introduced by Tversky and Kahneman (1991). I will assume the following structure on preferences: If the agent has consumption $c_{t}$ today, her utility for consumption above $c_{t}$ is as described in Section 2, but she is more severely hit by consumption below $c_{t}$. Her utility of consumption $c_{t+1}$ in next period valued today is assumed to be

$$
\tilde{u}\left(c_{t+1} ; c_{t}\right)=\left\{\begin{array}{lll}
(1+\lambda) u\left(c_{t+1}\right)-\lambda u\left(c_{t}\right) & \text { if } \quad c_{t+1}<c_{t} \\
u\left(c_{t+1}\right) & \text { if } \quad c_{t+1} \geq c_{t}
\end{array}\right.
$$

where $\lambda>0$ is a coefficient of loss aversion. This function is depicted in Figure 1. It is continuous, but has a kink at $c_{t}$. Notice that I do not assume that the utility function satisfies diminishing sensitivity (Kahneman and Tversky 1979), which would imply an S-shaped utility function in addition to the kink.

Assume for simplicity that there are only two periods, and the tax rate is determined at the beginning of the first period and will stay in place for both periods. When an agent casts her vote, she knows her income this period, but the income tomorrow is still unknown.

Figure 1 about here

The optimal tax rate then satisfies

$$
\begin{aligned}
{\left[T^{\prime}(\tau) \bar{y}-y_{t}\right] u^{\prime}\left(c_{t}\right)+\beta \int_{0}^{\infty}\left[T^{\prime}(\tau) \bar{y}-y_{t+1}\right] u\left(c_{t+1}\right) d F\left(y_{t+1} ; y_{t}, s_{t}\right) } \\
\quad+\beta \lambda \int_{0}^{c_{t}}\left[T^{\prime}(\tau) \bar{y}-y_{t+1}\right] u\left(c_{t+1}\right) d F\left(y_{t+1} ; y_{t}, s_{t}\right)=0 .
\end{aligned}
$$

A more positive signal $s_{t}$ leads to a new distribution of next period income $y_{t+1}$. As $\left[T^{\prime}(\tau) \bar{y}-y_{t+1}\right] u\left(c_{t+1}\right)$ is decreasing in $y_{t+1}$ this makes the expression on the left hand 
side of the equality negative. Because the second order condition holds, this expression is decreasing in $\tau$, so the optimal tax rate is now lower. When $\lambda>0$, we get an extra integral in the equation with similar properties, so the effect of the signal $s_{t}$ is stronger. Hence the effect on the tax rate is also stronger. By a similar reasoning, a negative signal would lead to a stronger increase in the preferred tax rate the more loss averse the agent is. Hence loss aversion make small changes about expectations about the future have strong effect on preferences, and hence make agents look more far sighted than they really are. Consequently, loss aversion may be one explanation for the large weight put on permanent income by the voters in my sample. If we believe the classic explanation of such a results, that voters are extremely forward looking, to be false, this gives an indication of the loss aversion theory being true.

\section{Conclusion}

From a standard model of forward looking voters in an intertemporal setup, I found that if policy changes are costly, then preferences for redistribution will depend on the discounted present value of expected future income where the discount factor is reduced because of partial persistence. To test this prediction, I studied the impact of transitory versus permanent income on party preferences using Norwegian electoral data. This was done using a random utility model with individual specific effects. To identify the effect of permanent income, I used the answer to questions about the agent's expected future economic situation. This does not affect income today and should not have a direct influence on party preferences. However, it does affect future income. This effect was estimated and used to construct a proxy for permanent income.

The first conclusion was that a high income has the expected effect of increasing the probability of voting Conservative and reducing the probability of voting Socialist. Furthermore, the effect of transitory income is virtually absent once permanent income is taken into account. Hence it seems voters are extremely forward looking. However, there are some caveats to this conclusion. Alternative explanations based on misunderstanding of the expectations-question and loss aversion were discussed. However, there is probably considerable evidence for forward looking voting. 


\section{References}

Alesina, A. F., and E. La Ferrara (2002): "Preferences for redistribution in the land of opportunities." CEPR Discussion Paper 3155.

Arellano, M., and S. Bond (1991): "Some tests of specification for panel data: Monte Carlo evidence and an application to employment equations." Review of Economic Studies 58: 277-97.

Bénabou, R., and E. Ok: "Social mobility and the demand for redistribution: The POUM hypothesis:" Quarterly Journal of Economics 116:447-87.

Browning, M., and A. Lusardi (1996): "Household Saving: Micro Theories and Micro Facts." Journal of Economic Literature 34: 1797-1855.

Chamberlain, G. (1980): "Analysis of covariance with qualitative data." Review of Economic Studies 47: 225-38.

Chamberlain (1984): "Panel data." In Z. Griliches and M. D. Intiligator (eds.) Handbook of Econometrics, vol. 2, Amsterdam: Elsevier Science.

Coate, S. and S. Morris (1999): "Policy persistence." American Economic Review 89: 1327-36.

Corneo, G., and H. P. Grüner (2002): "Individual preferences for political redistribution." Journal of Public Economics 83: 83-107.

Deaton, A. (1992): Understanding Consumption, Cambridge: Cambridge University Press.

Downs, A. (1957): An economic theory of democracy. New York : Harper \& Row.

Friedman, M. (1957): A Theory of the Consumption Function. Princeton: Princeton University Press.

Hassler, J., J.V. Rodriguez Mora, K. Storesletten, and F. Zilibotti (2003a): "The Survival of the Welfare State." American Economic Review 93: 87112.

Hassler, J., P. Krusell, K. Storesletten, and F. Zilibotti (2003b): "The Dynamics of Government." Unpublished paper. 
Husted, T. A. (1989): "Nonmonotonic demand for income redistribution benefits: The case of AFDC." Sourthern Economic Journal 55: 710-27.

Kahneman, D., and A. Tversky (1979): "Prospect theory: An analysis of decision under risk." Econometrica 47: 263-91.

Kiberg, D., K. Strømsnes, E. Vasstrand, and K. Klarén (2000): "De norske valgundersøkelsene 1977, 1981, 1985, 1989, 1993 og 1997. Dokumentasjon og frekvenser." NSD Rapport 117 (in Norwegian).

Krusell, P., V. Quadrini, and J.-V. Ríos-Rull (1997): "Politico-economic equilibrium and economic growth." Journal of Economic Dynamics and Control 21: 243-72.

Krusell, P., and J.-V. Ríos-Rull (1999): "On the size of U.S. government: Political economy in the neoclassical growth model." American Economic Review 89: 1156-81.

Lind, J. T. (2004): "Do the rich vote conservative because they are rich?" Essay 2 in this dissertation.

Meltzer, A., and S. Richard (1981): "A rational theory of the size of government." Journal of Political Economy 89: 914-27.

Rasch, B. E., (2003): "Det politiske landskap. Stortingsrepresentantenes oppfatning av konfliktstrukturen i partisystemet." Tidsskrift for Samfunnsforskning 44: 37-66. (in Norwegian).

Ravallion, M., and M. Lokshin (2000): "Who wants to redistribute? The tunnel effect in 1990s Russia." Journal of Public Economics 76: 87-104.

Roemer, J. E. (1998): "Why the poor do not expropriate the rich: An old argument in new garb." Journal of Public Economics 70: 399-424.

Roemer, J. E. (1999): "The democratic political economy of progressive income taxation." Econometrica 67: 1-19.

Stokey, N. L, and R. E. Lucas (with E.C. Prescott) (1989): Recursive Methods in Economic Dynamics. Cambridge, MA: Harvard University Press. 
Tversky, A, and D. Kahneman (1991): "Loss aversion in risk less choice: A reference-dependent model." Quarterly Journal of Economics 106: 103961.

van der Vaart, A. W. (1998): Asymptotic Statistics. Cambridge: Cambridge University Press.

White, H. (1984): Asymptotic Theory for Econometricians. Orlando: Academic Press. 
Table 1

Proxies for permanent income

\begin{tabular}{|c|c|c|c|c|c|c|c|}
\hline Party & Variable & $\begin{array}{c}(1) \\
\text { Random effects }\end{array}$ & $\begin{array}{c}(2) \\
\text { Fixed effects }\end{array}$ & $\begin{array}{c}(3) \\
\text { Random effects }\end{array}$ & $\begin{array}{c}\text { (4) } \\
\text { Random effects }\end{array}$ & $\begin{array}{c}(5) \\
\text { Fixed effects }\end{array}$ & $\begin{array}{c}\text { (6) } \\
\text { Random effects }\end{array}$ \\
\hline \multirow[t]{2}{*}{ Socialist } & Income & $\begin{array}{c}0.172 \\
(0.165)\end{array}$ & $\begin{array}{c}0.196 \\
(0.363)\end{array}$ & $\begin{array}{c}-0.006 \\
(0.100)\end{array}$ & $\begin{array}{c}0.178 \\
(0.164)\end{array}$ & $\begin{array}{c}0.176 \\
(0.366)\end{array}$ & $\begin{array}{c}-0.004 \\
(0.100)\end{array}$ \\
\hline & Exp. better ec. & & & & $\begin{array}{l}-0.210 \\
(0.224)\end{array}$ & $\begin{array}{l}-0.275 \\
(0.293)\end{array}$ & $\begin{array}{l}-0.125 \\
(0.130)\end{array}$ \\
\hline \multirow[t]{3}{*}{ Centrist } & Income & $\begin{array}{c}0.047 \\
(0.150)\end{array}$ & $\begin{array}{c}0.098 \\
(0.302)\end{array}$ & $\begin{array}{l}-0.314 \\
(0.073)\end{array}$ & $\begin{array}{c}0.052 \\
(0.149)\end{array}$ & $\begin{array}{c}0.101 \\
(0.307)\end{array}$ & $\begin{array}{l}-0.320 \\
(0.073)\end{array}$ \\
\hline & Exp. worse ec. & & & & $\begin{array}{c}0.150 \\
(0.208)\end{array}$ & $\begin{array}{c}0.251 \\
(0.310)\end{array}$ & $\begin{array}{l}-0.140 \\
(0.091)\end{array}$ \\
\hline & Exp. better ec. & & & & $\begin{array}{l}-0.012 \\
(0.188)\end{array}$ & $\begin{array}{c}0.095 \\
(0.306)\end{array}$ & $\begin{array}{l}-0.024 \\
(0.092)\end{array}$ \\
\hline \multirow[t]{3}{*}{ Conservative } & Income & $\begin{array}{c}0.514 \\
(0.141)\end{array}$ & $\begin{array}{c}0.218 \\
(0.301)\end{array}$ & $\begin{array}{c}0.570 \\
(0.065)\end{array}$ & $\begin{array}{c}0.479 \\
(0.142)\end{array}$ & $\begin{array}{c}0.184 \\
(0.305)\end{array}$ & $\begin{array}{c}0.553 \\
(0.065)\end{array}$ \\
\hline & Exp. worse ec. & & & & $\begin{array}{l}-0.662 \\
(0.268)\end{array}$ & $\begin{array}{l}-0.281 \\
(0.450)\end{array}$ & $\begin{array}{l}-0.466 \\
(0.106)\end{array}$ \\
\hline & Exp. better ec. & & & & $\begin{array}{c}0.510 \\
(0.186)\end{array}$ & $\begin{array}{c}0.618 \\
(0.344)\end{array}$ & $\begin{array}{c}0.577 \\
(0.087)\end{array}$ \\
\hline \multirow[t]{3}{*}{ Progress } & Income & $\begin{array}{c}0.011 \\
(0.181)\end{array}$ & $\begin{array}{l}-0.605 \\
(0.441)\end{array}$ & $\begin{array}{l}-0.035 \\
(0.123)\end{array}$ & $\begin{array}{c}0.014 \\
(0.180)\end{array}$ & $\begin{array}{l}-0.622 \\
(0.459)\end{array}$ & $\begin{array}{l}-0.035 \\
(0.122)\end{array}$ \\
\hline & Exp. worse ec. & & & & $\begin{array}{c}0.204 \\
(0.254)\end{array}$ & $\begin{array}{c}0.571 \\
(0.545)\end{array}$ & $\begin{array}{c}0.099 \\
(0.169)\end{array}$ \\
\hline & Exp. better ec. & & & & $\begin{array}{c}0.136 \\
(0.228)\end{array}$ & $\begin{array}{l}-0.190 \\
(0.464)\end{array}$ & $\begin{array}{c}0.371 \\
(0.149)\end{array}$ \\
\hline $\log L$ & & -2062.5 & -374.4 & -7601.6 & -2043.9 & -366.8 & -7544.6 \\
\hline Observations & & 718 & 718 & 2952 & 718 & 718 & 2952 \\
\hline Periods & & 2 & 2 & 2 & 2 & 2 & 2 \\
\hline Ind. effects & & Random & Fixed & Random & Random & Fixed & Random \\
\hline Sample & & Changers & Changers & Full & Changers & Changers & Full \\
\hline LR (8) & & & & & 37.26 & 15.298 & 114 \\
\hline $\mathrm{p}$-value & & & & & {$\left[1.03 \times 10^{-05}\right]$} & {$\left[5.36 \times 10^{-02}\right]$} & {$\left[5.72 \times 10^{-21}\right]$} \\
\hline
\end{tabular}

Values are coefficient on income measured relative to period averages. Standard errors in parenthesis. Control variables are age, two categories of education, and dummy variables for sex, marital status, student, retired, staying at home, and year. Sex and age are omitted for the fixed effects model. Estimation is by simulated maximum likelihood with 10 simulations per observation. LR is likelihood ration test against columns (1)-(5). 
Table 2

Results from the VAR model of income dynamics

\begin{tabular}{|c|c|c|c|c|c|c|c|c|c|}
\hline & \multicolumn{3}{|c|}{ Unconstrained estimation } & \multicolumn{3}{|c|}{ Constrained estimation } & \multicolumn{3}{|c|}{ Constrained estimation, $\phi=.2$} \\
\hline & Income & $\begin{array}{c}\text { Worse } \\
\text { economy }\end{array}$ & $\begin{array}{c}\text { Better } \\
\text { economy }\end{array}$ & Income & $\begin{array}{c}\text { Worse } \\
\text { economy }\end{array}$ & $\begin{array}{c}\text { Better } \\
\text { economy }\end{array}$ & Income & $\begin{array}{c}\text { Worse } \\
\text { economy }\end{array}$ & $\begin{array}{c}\text { Better } \\
\text { economy }\end{array}$ \\
\hline Constant & $\begin{array}{c}0.459 \\
(0.020)\end{array}$ & $\begin{array}{c}0.168 \\
(0.015)\end{array}$ & $\begin{array}{c}0.212 \\
(0.017)\end{array}$ & $\begin{array}{c}0.459 \\
(0.009)\end{array}$ & $\begin{array}{c}0.147 \\
(0.009)\end{array}$ & $\begin{array}{c}0.190 \\
(0.009)\end{array}$ & $\begin{array}{c}1.048 \\
(0.009)\end{array}$ & $\begin{array}{c}0.147 \\
(0.009)\end{array}$ & $\begin{array}{c}0.190 \\
(0.009)\end{array}$ \\
\hline Income & $\begin{array}{c}0.546 \\
(0.014)\end{array}$ & $\begin{array}{l}-0.006 \\
(0.011)\end{array}$ & $\begin{array}{l}-0.018 \\
(0.012)\end{array}$ & $\begin{array}{c}0.546 \\
(0.014)\end{array}$ & 0 & 0 & $\begin{array}{c}0.002 \\
(0.000)\end{array}$ & 0 & 0 \\
\hline $\begin{array}{l}\text { Worse } \\
\text { economy }\end{array}$ & $\begin{array}{l}-0.029 \\
(0.025)\end{array}$ & $\begin{array}{c}0.171 \\
(0.019)\end{array}$ & $\begin{array}{l}-0.010 \\
(0.021)\end{array}$ & $\begin{array}{l}-0.029 \\
(0.025)\end{array}$ & $\begin{array}{c}0.186 \\
(0.018)\end{array}$ & 0 & $\begin{array}{l}-0.076 \\
(0.031)\end{array}$ & $\begin{array}{c}0.186 \\
(0.018)\end{array}$ & 0 \\
\hline $\begin{array}{l}\text { Better } \\
\text { economy }\end{array}$ & $\begin{array}{c}0.150 \\
(0.022)\end{array}$ & $\begin{array}{l}-0.044 \\
(0.016)\end{array}$ & $\begin{array}{c}0.250 \\
(0.018)\end{array}$ & $\begin{array}{c}0.150 \\
(0.022)\end{array}$ & 0 & $\begin{array}{c}0.251 \\
(0.018)\end{array}$ & $\begin{array}{c}0.171 \\
(0.027)\end{array}$ & 0 & $\begin{array}{c}0.251 \\
(0.018)\end{array}$ \\
\hline Implied $\pi \mathrm{s}$ & & & & $\begin{array}{c}0.235 \\
(0.012)\end{array}$ & $\begin{array}{l}-0.012 \\
(0.009)\end{array}$ & $\begin{array}{c}0.064 \\
(0.018)\end{array}$ & $\begin{array}{c}0.012 \\
\left(2.08 \times 10^{-17}\right)\end{array}$ & $\begin{array}{l}-0.020 \\
(0.007)\end{array}$ & $\begin{array}{c}0.045 \\
(0.007)\end{array}$ \\
\hline $\begin{array}{l}\mathrm{R}^{2} \\
\mathrm{~F}(2,2948) \\
\text { p-value }\end{array}$ & 0.335 & 0.014 & 0.052 & $\begin{array}{c}0.345 \\
0.000 \\
{[1]} \\
\end{array}$ & $\begin{array}{c}0.035 \\
3.780 \\
{[0.023]}\end{array}$ & $\begin{array}{c}0.065 \\
1.281 \\
{[0.278]} \\
\end{array}$ & $\begin{array}{c}0.020 \\
730.573 \\
{\left[2.018 \times 10^{-258}\right]} \\
\end{array}$ & $\begin{array}{c}0.035 \\
3.780 \\
{[0.023]} \\
\end{array}$ & $\begin{array}{c}0.065 \\
1.281 \\
{[0.278]} \\
\end{array}$ \\
\hline
\end{tabular}

Values are parameters on one period lagged variables. Income is measured relative to period average. Standard errors in parenthesis. Standard errors of derived $\pi \mathrm{s}$ are estimated using bootstrapping (100 iterations). F-test is against the unconstrained model. 
Table 3

Effect of permanent income on party choice

\begin{tabular}{|c|c|c|c|c|}
\hline & & $\begin{array}{c}\text { (1) } \\
\text { Random effects }\end{array}$ & $\begin{array}{c}(2) \\
\text { Fixed effects }\end{array}$ & $\begin{array}{c}\text { (3) } \\
\text { Random effects }\end{array}$ \\
\hline \multirow[t]{4}{*}{ Socialist } & $\mathrm{a}$ & 0.17 & 0.17 & -0.02 \\
\hline & & $(0.14)$ & $(0.47)$ & $(0.11)$ \\
\hline & b & -4.58 & -5.86 & -2.20 \\
\hline & & $(6.48)$ & (6.88) & (1.64) \\
\hline \multirow[t]{4}{*}{ Centre } & $\mathrm{a}$ & 0.06 & 0.05 & -0.32 \\
\hline & & $(0.10)$ & $(0.37)$ & $(0.12)$ \\
\hline & b & -1.00 & -0.22 & 0.51 \\
\hline & & $(4.59)$ & $(9.05)$ & $(0.97)$ \\
\hline \multirow[t]{4}{*}{ Conservative } & $\mathrm{a}$ & 0.51 & 0.17 & 0.56 \\
\hline & & $(0.12)$ & $(0.38)$ & $(0.07)$ \\
\hline & $\mathrm{b}$ & 9.94 & 10.36 & 10.73 \\
\hline & & $(8.65)$ & (13.88) & $(1.96)$ \\
\hline \multirow[t]{4}{*}{ Progress } & $\mathrm{a}$ & 0.04 & -0.49 & -0.05 \\
\hline & & $(0.17)$ & $(0.50)$ & $(0.13)$ \\
\hline & $b$ & 0.78 & -5.71 & 4.89 \\
\hline & & $(11.41)$ & $(16.73)$ & $(1.62)$ \\
\hline \multirow[t]{4}{*}{ Socialist } & $\beta$ & -3.34 & -4.31 & -1.70 \\
\hline & & $(5.13)$ & $(5.48)$ & $(1.23)$ \\
\hline & $\zeta$ & -0.37 & -0.36 & -0.29 \\
\hline & & $(0.17)$ & $(0.27)$ & $(0.58)$ \\
\hline \multirow[t]{4}{*}{ Centre } & $\beta$ & -0.70 & -0.12 & 0.07 \\
\hline & & $(3.61)$ & (7.19) & $(0.76)$ \\
\hline & $\zeta$ & -0.42 & -0.79 & -6.56 \\
\hline & & $(0.12)$ & $(0.47)$ & $(2.35)$ \\
\hline \multirow[t]{4}{*}{ Conservative } & $\beta$ & 8.12 & 8.10 & 8.77 \\
\hline & & $(6.83)$ & (10.98) & (1.49) \\
\hline & $\zeta$ & -0.22 & -0.28 & -0.22 \\
\hline & & $(0.04)$ & $(0.04)$ & $(0.02)$ \\
\hline \multirow[t]{4}{*}{ Progress } & $\beta$ & 0.63 & -4.86 & 3.69 \\
\hline & & $(9.07)$ & $(13.31)$ & $(1.28)$ \\
\hline & $\zeta$ & -0.23 & -0.17 & -0.33 \\
\hline & & $(0.22)$ & $(0.13)$ & $(0.06)$ \\
\hline \multicolumn{2}{|l|}{ Log likelihood } & -2048.81 & -368.54 & -7551.05 \\
\hline \multicolumn{2}{|l|}{ Observations } & 718 & 718 & 2952 \\
\hline \multicolumn{2}{|l|}{ Periods } & 2 & 2 & 2 \\
\hline \multicolumn{2}{|l|}{ Ind. Effects } & Random & Fixed & Random \\
\hline \multicolumn{2}{|l|}{ Sample } & Changers & Changers & Full \\
\hline \multicolumn{2}{|l|}{ LR (4) } & 9.81 & 3.48 & 12.89 \\
\hline \multicolumn{2}{|l|}{ p-value } & {$[0.04]$} & {$[0.48]$} & {$[0.01]$} \\
\hline
\end{tabular}

Numbers are coefficients on $a$ and $b$, the coefficients on the transitory income and future income components, and derived $\beta \mathrm{s}$ and $\zeta_{\mathrm{s}}$, the coefficients on the relevant measure of income and the share of transitory income in this measure. Standard errors in parenthesis. Control variables are age, two categories of education, and dummy variables for sex, marital status, student, retired, staying at home, and year. Sex and age are omitted for the fixed effects model. Estimation is by simulated maximum likelihood with 10 simulations per observation. Standard errors are estimated using bootstrapping with 20 replications. LR (4) is an LR-test against the unrestricted models in Table 1. 
Table 4

Effect of permanent income on party choice with restricted $\phi=0.2$

(1) (2)

Random effects

\begin{tabular}{lcc}
\hline Socialist & $\mathrm{a}$ & 0.17 \\
& & $(0.14)$ \\
& $\mathrm{b}$ & -6.44 \\
& & $(4.08)$ \\
Centre & $\mathrm{a}$ & 0.06 \\
& & $(0.10)$ \\
& $\mathrm{b}$ & -1.70 \\
& & $(3.17)$ \\
Conservative & $\mathrm{a}$ & 0.51 \\
& & $(0.12)$ \\
& $\mathrm{b}$ & 13.95 \\
& & $(6.31)$ \\
Progress & $\mathrm{a}$ & 0.04 \\
& & $(0.17)$ \\
& $\mathrm{b}$ & 0.38 \\
& & $(4.50)$
\end{tabular}

Fixed effects

0.17

$(0.47)$

$-8.44$

$(6.88)$

0.05

$(0.37)$

$-1.08$

$(6.65)$

0.17

(0.39)

13.45

(10.32)

$-0.49$

$(0.53)$

$-8.80$

(11.81)

$-8.16$

(6.87)

$-0.03$

(0.11)

$-1.02$

(6.63)

$-0.06$

(1.28)

13.45

(10.12)

0.00

$(0.03)$

$-9.18$

(11.57)

0.04

$(0.25)$
$-367.94$
718
2

Fixed

Changers

2.29
(3)

Random effects

$-0.02$

(0.11)

$-2.89$

(2.28)

$-0.32$

$(0.12)$

1.12

(1.48)

0.56

(0.07)

14.70

(2.57)

$-0.06$

(0.13)

5.90

(2.51)

$-2.87$

(2.23)

$-0.01$

$(0.25)$

0.78

(1.48)

$-0.43$

(0.98)

15.08

(2.55)

0.02

(0.01)

5.77

(2.50)

$-0.02$

(0.07)

$-7547.37$

2952

2

Random

Full

5.53

[0.24]

p-value

[0.23]

[0.68]

Numbers are coefficients on $a$ and $b$, the coefficients on the transitory income and future income components, and derived $\beta$ s and $\zeta$ s, the coefficients on the relevant measure of income and the share of transitory income in this measure. Standard errors in parenthesis. Control variables are age, two categories of education, and dummy variables for sex, marital status, student, retired, staying at home, and year. Sex and age are omitted for the fixed effects model.

Estimation is by simulated maximum likelihood with 10 simulations per observation. Standard errors are estimated using bootstrapping with 20 replications. LR (4) is an LR-test against the unrestricted models in Table 1. 
Table 5

Effect of permanent income on party choice in the restricted model

\begin{tabular}{lccc}
\hline \hline & $(1)$ & $(2)$ & $(3)$ \\
& Random effects & Fixed effects & Random effects \\
\hline Socialist & -4.59 & -7.80 & -2.75 \\
& $(3.62)$ & $(6.90)$ & $(2.04)$ \\
Centre & -1.13 & -0.73 & -1.14 \\
& $(2.72)$ & $(6.71)$ & $(1.63)$ \\
Conservative & 16.68 & 13.65 & 17.67 \\
& $(6.82)$ & $(9.05)$ & $(2.83)$ \\
Progress & 0.61 & -10.47 & 5.04 \\
& $(3.79)$ & $(12.05)$ & $(2.43)$ \\
log L & & & \\
Observations & -2049.94 & -368.83 & -7593.74 \\
Periods & 718 & 718 & 2952 \\
Ind. Effects & 2 & 2 & 2 \\
Sample & Random & Fixed & Random \\
LR (4) & Changers & Changers & Full \\
p-value & 6.50 & 1.76 & 92.74 \\
\hline
\end{tabular}

Values are coefficient on the estimated measure of permanent income, relative to averages. Standard errors in parenthesis. Control variables are age, two categories of education, and dummy variables for sex, marital status, student, retired, staying at home, and year. Sex and age are omitted for the fixed effects model. Estimation is by simulated maximum likelihood with 10 simulations per observation. Standard errors are estimated using bootstrapping with 20 replications. $\zeta=0$ and $\phi=0.2$ are assumed. LR (4) is the test is against $\zeta$ unrestricted, as in Table 4. 
Table 6

Disaggregating the permanent income proxy

\begin{tabular}{|c|c|c|c|c|}
\hline & & $\begin{array}{c}\text { (1) } \\
\text { Random effects }\end{array}$ & $\begin{array}{c}(3) \\
\text { Fixed effects }\end{array}$ & $\begin{array}{c}\text { (4) } \\
\text { Random effects }\end{array}$ \\
\hline \multirow[t]{6}{*}{ Socialist } & \multirow[t]{2}{*}{ Income } & 13.80 & 15.41 & -1.21 \\
\hline & & (11.18) & $(37.92)$ & $(9.27)$ \\
\hline & \multirow[t]{2}{*}{ Worse economy } & -13.06 & -18.54 & -3.53 \\
\hline & & $(6.19)$ & $(13.55)$ & $(10.12)$ \\
\hline & \multirow[t]{2}{*}{ Better economy } & -4.67 & -6.12 & -2.80 \\
\hline & & $(10.68)$ & $(14.43)$ & $(2.00)$ \\
\hline \multirow[t]{6}{*}{ Centre } & \multirow[t]{2}{*}{ Income } & 5.39 & 4.71 & -26.55 \\
\hline & & $(8.25)$ & $(30.80)$ & $(9.38)$ \\
\hline & \multirow[t]{2}{*}{ Worse economy } & -7.74 & -12.81 & 7.10 \\
\hline & & $(4.52)$ & $(10.53)$ & $(6.78)$ \\
\hline & \multirow[t]{2}{*}{ Better economy } & -0.26 & 2.34 & -0.54 \\
\hline & & $(11.66)$ & $(14.33)$ & (1.44) \\
\hline \multirow[t]{6}{*}{ Conservative } & \multirow[t]{2}{*}{ Income } & 40.66 & 14.78 & 44.79 \\
\hline & & $(9.48)$ & $(31.47)$ & $(5.76)$ \\
\hline & \multirow[t]{2}{*}{ Worse economy } & 33.84 & 14.26 & 23.82 \\
\hline & & $(14.70)$ & $(15.02)$ & $(11.32)$ \\
\hline & \multirow[t]{2}{*}{ Better economy } & 11.36 & 13.90 & 12.84 \\
\hline & & $(27.75)$ & $(41.57)$ & $(2.83)$ \\
\hline \multirow[t]{6}{*}{ Progress } & \multirow[t]{2}{*}{ Income } & 3.80 & -37.76 & -4.19 \\
\hline & & $(14.06)$ & $(40.38)$ & $(10.44)$ \\
\hline & \multirow[t]{2}{*}{ Worse economy } & -10.51 & -28.71 & -5.03 \\
\hline & & $(7.33)$ & $(16.96)$ & $(12.93)$ \\
\hline & \multirow[t]{2}{*}{ Better economy } & 3.07 & -4.17 & 8.26 \\
\hline & & $(12.00)$ & $(25.49)$ & $(3.27)$ \\
\hline \multicolumn{2}{|l|}{$\log L$} & -2043.76 & -367.22 & -7543.72 \\
\hline \multicolumn{2}{|l|}{ Observations } & 718 & 718 & 2952 \\
\hline \multicolumn{2}{|l|}{ Periods } & 2 & 2 & 2 \\
\hline \multicolumn{2}{|l|}{ Ind. effects } & Random & Fixed & Random \\
\hline \multicolumn{2}{|l|}{ Sample } & Changers & Changers & Full \\
\hline \multicolumn{2}{|l|}{ LR (8) } & 12.36 & 3.22 & 100.04 \\
\hline \multicolumn{2}{|l|}{$p$-value } & {$[0.14]$} & {$[0.92]$} & {$\left[4.19 \times 10^{-18}\right]$} \\
\hline
\end{tabular}

Values are the three different estimates of the coefficient on permanent income. Standard errors in parenthesis. Control variables are age, two categories of education, and dummy variables for sex, marital status, student, retired, staying at home, and year. Sex and age are omitted for the fixed effects model. Estimation is by simulated maximum likelihood with 10 simulations per observation. Standard errors are estimated using bootstrapping with 20 replications. $\zeta=0$ and $\phi=0.2$ are assumed. LR (8) is a likelihood test of the unrestricted model shown here against the restricted model of Table 5 . 


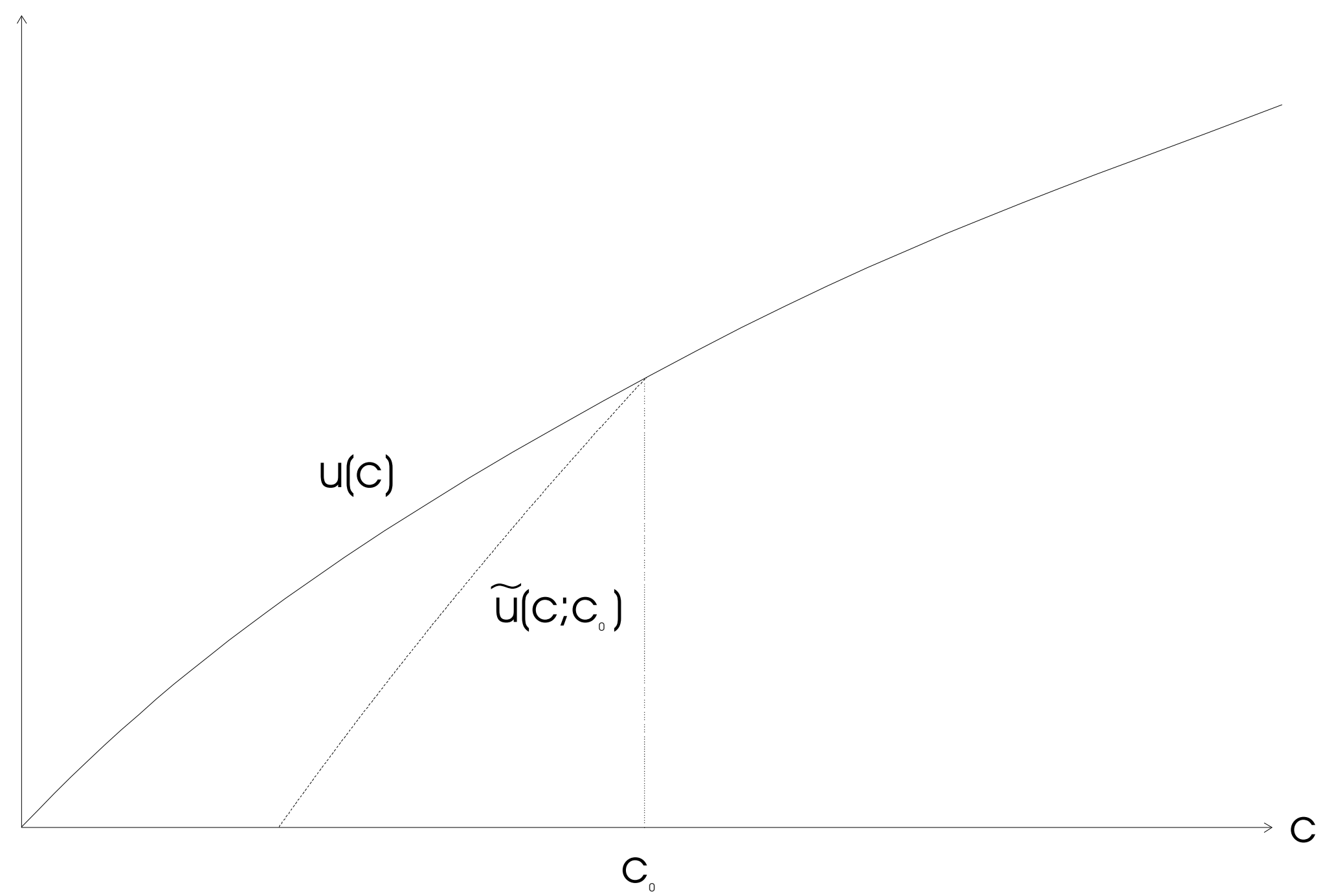

Figure 1: Utility function with loss aversion, but not diminishing sensitivity, when consumption was $c_{0}$ last period. 